\title{
Argon plasma coagulation for the resolution of basket impaction from large common bile duct stones
}

Authors

Institutions
Patommatat Bhanthumkomol' ${ }^{1}$ Pitulak Aswakul ${ }^{2}$, Varayu Prachayakul ${ }^{3}$

GI Unit, Department of Medicine, Thammasat University Hospital, Pathumthani, Thailand

2 Liver and Digestive Institute, Samitivej Sukhumvit Hospital, Bangkok, Thailand

Siriraj GI Endoscopy Center, Siriraj Hospital; Division of Gastroenterology, Department of Internal Medicine, Faculty of Medicine, Mahidol University, Bangkok, Thailand submitted 4. August 2015 accepted after revision 4. January 2016

\section{Bibliography}

Dol http://dx.doi.org/ 10.1055/s-0042-100905 Published online: 10.2.2016 Endoscopy International Open 2016; 04: E389-E390

(c) Georg Thieme Verlag KG Stuttgart · New York E-ISSN 2196-9736

\section{Corresponding author}

\section{Varayu Prachayakul, MD}

Siriraj GI Endoscopy Center Siriraj Hospital

Division of Gastroenterology

Department of Internal

Medicine

Faculty of Medicine

Mahidol University

Bangkok 10700

Thailand

Fax: +66-2-4120188

kaiyjґ@gmail.com

\section{Introduction}

$\nabla$

One of the most common indications for endoscopic retrograde cholangiopancreatography (ERCP) is choledocholithiasis - the occurrence of stones in the common bile duct (CBD). However, in approximately $5 \%$ to $10 \%$ of cases, the procedure fails, especially in a patient with large or impacted stones [1]. An uncommon adverse event during ERCP with CBD stone clearance is impaction of the basket-stone complex, which sometimes leads to unnecessary surgical procedures such as laparoscopy or even exploratory laparotomy. This report describes a patient in whom argon plasma coagulation (APC) was used to resolve basket-stone impaction.

\section{Case report \\ $\nabla$}

A 93-year-old man, with no pre-existing illness, presented with abdominal pain, fever, and jaundice of several days' duration. His complete blood cell count indicated leukocytosis with a predominance of neutrophils. Liver chemistries showed increased total and direct bilirubin levels of 5.6 and $4.8 \mathrm{mg} / \mathrm{dL}$, respectively; aspartate transaminase of $45 \mathrm{U} / \mathrm{L}$; alanine transaminase of $42 \mathrm{U} / \mathrm{L}$; and an elevated alkaline phosphatase level of $321 \mathrm{U} / \mathrm{L}$. Thus, acute ascending cholangitis was suspected. Computed tomography showed four large $(1.5-2.0 \mathrm{~cm})$ stones in the CBD. Percutaneous trans-hepatic biliary drainage was immediately performed to relieve the obstruction, and intravenous antibiotics were administered. This procedure was recommended because of the presence of multiple, large stones that would be difficult to remove completely, as well as the patient's advanced age. His condition subsequently improved, so that he was able to provide fully informed consent to undergo ERCP and CBD clearance.
For this procedure, performed 1 week later, the patient was placed in a left lateral decubitus position and intravenous anesthesia (propofol) was administered. Following duodenal intubation and CBD cannulation with a standard sphincterotome, a cholangiogram was obtained that revealed a dilated CBD $(1.5-2.2 \mathrm{~cm})$ and four filling defects, shaped like polygons, located in the mid to distal portion ( $\bullet$ Fig.1). Sphincterotomy followed by endoscopic papillary balloon dilation was performed up to $15 \mathrm{~mm}$ (CRE Wireguided Balloon Dilator; Boston Scientific, Marlborough, Massachusetts, USA). The three distally located CBD stones were successfully removed with a Dormia basket (TetraCatch; Olympus, Shinjuku, Tokyo, Japan).

During an attempt to remove the last stone, the basket-stone complex was impacted at the intraduodenal portion of the CBD and could not be pulled out into the duodenum. This impaction also blocked insertion of the catheter for a largeballoon dilation procedure. Therefore, mechanical lithotripsy was attempted with a Soehendra lithotripter. However, this failed because of device malfunction. The basket-stone complex was then manipulated with rat-tooth forceps; however, this also failed, even after extended sphincterotomy. Subsequent attempts to push the basketstone complex back into the proximal CBD with an extraction balloon similarly failed.

Next, we decided to use APC ( $100 \mathrm{~W}$, force mode) to cut two of the four basket wires and release the basket-stone complex ( Video $\mathbf{1}$ ). The cutting time was 3 to 4 minutes. The basket was released from the impacted stone and retrieved easily by pulling it back into the duodenoscope. Finally, a 10 -Fr double-pigtail stent ( $5 \mathrm{~cm}$ in length) was inserted across the distal CBD, and the procedure was terminated. The patient was rescheduled to undergo CBD stone clearance 12 weeks later, but he died 8 weeks after the procedure as a result of 


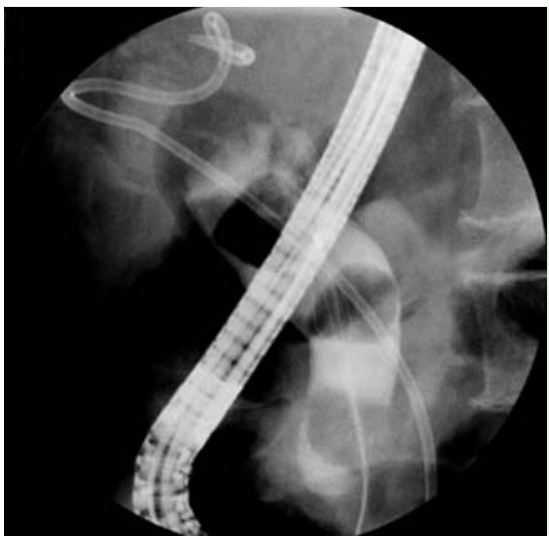

Fig. 1 Cholangiogram showing multiple large stones in the common bile duct of a 93-yearold man with no preexisting illness, presenting with abdominal pain, fever, and jaundice of several days' duration.

reactivation of tuberculosis complicated by severe hospital-acquired pneumonia.

\section{Discussion \\ $\nabla$}

Basket impaction occurs in $0.8 \%$ to $5.9 \%$ of all ERCP procedures [1]. Failure to resolve such impaction can lead to emergency laparoscopy or open surgery. Reports have described the use of various techniques and accessories to solve this problem, including extracorporeal shock wave lithotripsy [2], laser lithotripsy with a stone recognition system [3], endoscopic papillary balloon dilation [4], removal with biopsy or rat-tooth forceps [5,6], Dormia basketing [7], second mechanical lithotripsy [8], and removal via the percutaneous route with a cholangioscope [9] or goose neck snare [10]. However, the technique chosen for use in the clinical setting largely depends on the availability of devices and the endoscopist's expertise. To the best of our knowledge, the present report is the first describing the use of APC to destroy the basket wires and resolve this event. APC devices are available in most endoscopy units, and the technique does not require special training.

In summary, the use of APC to destroy basket wires is a safe, easy technique for resolving basket-stone impaction. It can be used as an alternative to emergency surgery in cases in which rescue lithotripters are unavailable or have failed. However, the technique requires visualization of the basket wire, such as when the impacted basket-stone complex is located within the intraduodenal portion of the CBD.

\section{Competing interests: None}

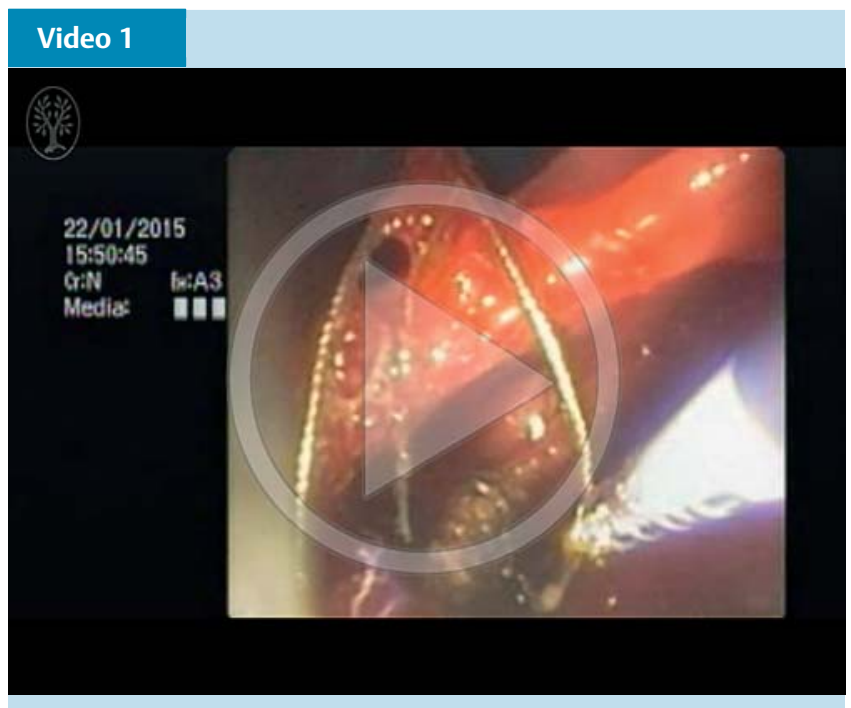

Use of an argon plasma coagulation catheter to cut the basket wires. Online content including video sequences viewable at: http://dx.doi.org/ 10.1055/s-0042-100905

\section{References}

1 Schneider MU, Matek W, Bauer $R$ et al. Mechanical lithotripsy of bile duct stones in 209 patients - effect of technical advances. Endoscopy 1988; 20: $248-253$

2 Nuehaus B, Safrany L. Complications of endoscopic sphinecterotomy and their treatment. Endoscopy 1981; 13: 197-199

3 Neuhaus H, Hoffmann W, Classen M. Endoscopic laser lithotripsy with an automatic stone recognition system for basket impaction in the common bile duct. Endoscopy 1992; 24: 596-599

4 Mabuchi M, Iwashita T, Yasuda I et al. Endoscopic papillary large balloon dilation as a salvage procedure for basket impaction during retrieval of common bile duct stones. Dig Dis Sci 2014; 5: 220-223

5 Ryozawa S, Iwano $\mathrm{H}$, Taba $\mathrm{K}$ et al. Successful retrieval of an impacted mechanical lithotripsy basket: a case report. Dig Endosc 2010; 22: S111-S113

6 Tahtacı M, İbiş M, Koruk İ et al. Endoscopic removal of fractured basket traction wire. Turk J Gastroenterol 2014; 25: 324-325

7 Khawaja FI, Ahmad MM. Basketing a basket: a novel emergency rescue technique. World J Gastrointest Endosc 2012; 4: 429-431

$8 \mathrm{Ng}$ EK, Lau JY, Chung SC et al. Retrieval of an impacted mechanical lithotripsy basket. Endoscopy 1997; 29: 128

9 Halfhide BC, Boeve ER, Laméris JS. Percutaneous release of Dormia baskets impacted in the common bile duct. Endoscopy 1997; 29: 48

$10 \mathrm{Kwon} \mathrm{JH}$, Lee JK, Lee JH et al. Percutaneous transhepatic release of an impacted lithotripter basket and its fractured traction wire using a goose-neck snare: a case report. Korean J Radiol 2011; 12: 247-251 